\title{
Modelo logístico de crescimento de cultivares crioulas de milho e de progênies de meios-irmãos maternos em função da soma térmica
}

\author{
Logistic growing model of corn creole cultivate and \\ maternal progenies of half-brothers as a function of thermal time \\ Marta Stochero Deprá ${ }^{*}$ Sidinei José Lopes ${ }^{\mathrm{II}}$ Gisele Noal $^{\mathrm{I}}$
Lia Rejane Silveira Reiniger ${ }^{\mathrm{II}}$ Débora Telles Cocco ${ }^{\mathrm{I}}$
}

\section{RESUMO}

O milho é uma das culturas mais produzidas no mundo, com ampla distribuição geográfica em razão de sua ampla variabilidade genética presente inclusive em cultivares crioulas. $O$ objetivo do estudo foi avaliar o crescimento das cultivares crioulas 'Amarelão', 'Lombo Baio'e 'Oito Carreiras', bem como, das respectivas progênies de meios-irmãos maternos. $O$ experimento foi conduzido no ano agrícola 2012/2013, em Santa Maria, RS. Foi utilizado o delineamento blocos ao acaso com quatro repetições e parcelas constituidas por duas linhas de cinco metros para as cultivares crioulas e delineamento em látice com três repetições e parcelas constituidas por uma linha de cinco metros para as progênies, com espaçamento entre plantas de $0.2 \mathrm{~m}$ e entre linhas de $0.9 \mathrm{~m}$. Foram realizadas cinco avaliações de altura de planta e número de folhas por planta e as curvas de crescimento foram ajustadas pelo modelo logístico em função da soma térmica acumulada. O modelo logístico foi adequado para o ajuste das curvas de crescimento. As cultivares crioulas 'Amarelão', 'Lombo Baio'e 'Oito Carreiras' apresentaram maior altura de plantas $e$ maior número de folhas por planta em comparação às respectivas progênies de meios-irmãos maternos.

Palavras-chave: Zea mays, crescimento de plantas, curvas de crescimento.

\section{ABSTRACT}

Corn is one of the crops that produce more in the world, it has a wise geographic distribution, because of the big genetic variability present including creole cultivates. The objective of this study was to evaluate the growing 'Amarelão' creole cultivate, 'Lombo baio' and 'Oito carreiras' and also maternal progenies of half-brothers of this cultivate. This experiment was done in the agricultural year 2012/2013 in Santa Maria, RS. It was used the block delineation aimlessly with four repetitions and constituted portions by two lines of five meters to the creole cultivates and lattice delineation with three repetitions and portions constituted by a five line meters to the progenies with a spacing of $0.2 \mathrm{~m}$ between each plant and between lines of $0.9 \mathrm{~m}$. It was done five evaluations of the plant height and leaves numbers by plant and the growing curves were adjusted by logistic model because of the thermal sum accumulated. The logistic model was adequate for the adjustment of the growing curves. The 'Amarelão' creole cultivate, 'Lombo baio' and 'Oito carreiras' presented the higher plant hight and the biggest number of leaves by plant in comparison to progenies of maternal half-brothers.

Key words: Zea mays, plants growing, growing curves.

\section{INTRODUÇ̃̃O}

O milho (Zea mays L.) é um cereal com adaptação a diferentes locais, isso se deve à ampla variabilidade genética que a espécie possui (PATERNIANI et al., 2000; TEIXEIRA \& COSTA, 2010), o que possibilitou a formação de genótipos adaptados a locais em que as restrições climáticas e de relevo tornam desvantajosa a utilização de cultivares melhoradas (ARAÚJO \& NASS, 2002). Para a manutenção desta variabilidade, torna-se necessária a conservação do germoplasma existente em populações crioulas de milho, a fim de reduzir as possibilidades de contaminação por cruzamento com cultivares melhoradas e, dessa forma, possa ser utilizado em programas de melhoramento para a obtenção de características de interesse (COIMBRA et al., 2010).

\footnotetext{
IUniversidade Federal de Santa Maria (UFSM), Campus Universitário, 97105-900, Santa Maria, RS, Brasil. E-mail: msdepra@yahoo.com.br. *Autor para correspondência.

IIDepartamento de Fitotecnia, UFSM, Santa Maria, RS, Brasil. 
Para que diferentes fontes de germoplasma possam ser utilizadas em programas de melhoramento, são necessárias maiores informações relativas ao comportamento dos diferentes acessos frente a estresses bióticos e abióticos e em relação às características agronômicas de interesse (TEIXEIRA \& COSTA, 2010). Portanto, avaliar o crescimento das plantas no decorrer de diferentes períodos do ciclo da cultura torna-se relevante, pois permite identificar características inerentes a cada genótipo estudado e selecionar aqueles que apresentam as características desejadas. A análise de crescimento de plantas é uma metodologia que avalia as bases fisiológicas da produção e a influência de variáveis genéticas, agronômicas e ambientais (SILVA et al., 2000). $\mathrm{O}$ crescimento vegetal pode ser quantificado por meio de modelos matemáticos que permitem definir quantitativamente hipóteses assumidas sobre o sistema real, permitindo deduzir suas consequências na agricultura, tais como, o manejo de certos sistemas ou de certas condições ambientais e avaliar a contribuição de diferentes partes da planta em seu crescimento final (DOURADO NETO et al., 1998).

Portanto, os objetivos do estudo foram caracterizar o crescimento em cultivares crioulas de milho 'Amarelão', 'Lombo Baio' e 'Oito Carreiras' e em progênies de meios-irmãos maternos oriundas do cruzamento destas cultivares crioulas.

\section{MATERIAL E MÉTODOS}

O experimento foi conduzido no município de Santa Maria - RS (2942'14.0”'S 53³4'24.3”W), no ano agrícola 2012/2013, com a semeadura sendo realizada em 15 de novembro de 2012 em Argissolo Vermelho Distrófico arênico (REINERT et al., 2007).

Foram utilizadas três cultivares crioulas de milho: 'Amarelão', 'Lombo Baio' e 'Oito Carreiras', todas com a coloração amarelo alaranjada dos grãos. 'Amarelão' com menor porte, 'Lombo Baio’ com sistema radicular mais desenvolvido e 'Oito Carreiras' com maior produtividade, quando comparadas aos demais genótipos produzidos no município de Ibarama, RS. Essas cultivares foram selecionadas por apresentarem características de interesse para o melhoramento participativo, cujas informações foram fornecidas pelos produtores, baseados em um conhecimento intrínseco, em busca de plantas com porte mais baixo e sistema radicular mais desenvolvido como forma de redução de perdas por acamamento, associada ao aumento de produtividade. Também foram utilizadas progênies de meios-irmãos maternos provenientes do cruzamento realizado na safra 2011/2012 entre as três cultivares crioulas. Foi realizada semeadura manual com uma semente por cova. Foi utilizado o delineamento experimental em látice $8 \times 8$ com três repetições para as progênies e delineamento blocos casualizados com quatro repetições para as cultivares. As parcelas das progênies foram constituídas por uma linha de cinco metros, enquanto, para as cultivares as parcelas foram constituídas de duas linhas de cinco metros, com espaçamento de $0.2 \mathrm{~m}$ entre plantas e de $0.9 \mathrm{~m}$ entre linhas. Foram realizadas duas aplicações de nitrogênio na forma de ureia, sendo a primeira realizada 20 dias após a semeadura e a segunda aplicação realizada 30 dias após a primeira, totalizando $180 \mathrm{~kg} \mathrm{ha}^{-1}$ de nitrogênio. Para controle de lagarta do cartucho (Spodoptera frugiperda), foram realizadas duas aplicações de inseticida, a primeira com deltametrina na dosagem de $200 \mathrm{~mL} \mathrm{ha}^{-1}$ do produto comercial e realizado 26 dias após a semeadura; e a segunda aplicação com triflumuron na dosagem de $50 \mathrm{~mL}$ ha $^{-1}$ do produto comercial, realizada 17 dias após a primeira aplicação. Ambas as aplicações de inseticida foram realizadas com pulverizador costal e jato dirigido ao cartucho das plantas. Não houve necessidade de controle de plantas daninhas.

Para as análises de crescimento foram realizadas cinco avaliações de altura de planta e número de folhas por planta em 18 progênies originadas da cultivar 'Amarelão', 25 progênies originadas da cultivar 'Lombo Baio' e nove progênies originadas da cultivar 'Oito Carreiras'. As avaliações foram iniciadas quando as plantas apresentavam seis folhas expandidas, a segunda avaliação foi realizada com oito folhas expandidas e a terceira avaliação quando as plantas encontravam-se com 12 folhas expandidas e em início de emissão do pendão. A quarta avaliação foi realizada no período de polinização das plantas, enquanto a última avaliação foi realizada no estádio de grão leitoso. A altura de planta foi medida em centímetros, até a última folha totalmente expandida, no ponto que separa a bainha do limbo foliar. Para o número de folhas, foram contabilizadas as folhas visíveis totalmente expandidas.

No decorrer do período experimental, foram registradas as temperaturas máximas e mínimas diárias do ar $\left({ }^{\circ} \mathrm{C}\right)$ provenientes da estação meteorológica situada no Campus da Universidade Federal de Santa Maria, para o cálculo da soma térmica acumulada. Para a estimativa da temperatura média diária $(\mathrm{Tm})$, foram utilizadas as temperaturas máxima e mínima do ar $\left({ }^{\circ} \mathrm{C}\right)$.

$\mathrm{STd}=(\mathrm{Tm}-\mathrm{Tb})$

Em que: $\mathrm{Tm}=$ temperatura média diária do ar $\left({ }^{\circ} \mathrm{C}\right) ; \mathrm{Tb}=$ temperatura base $\left({ }^{\circ} \mathrm{C}\right)=10^{\circ} \mathrm{C}$.

Ciência Rural, v.46, n.1, jan, 2016. 
A soma térmica acumulada ( $\mathrm{STa},{ }^{\circ} \mathrm{C}$ dia) foi obtida pelo somatório das somas térmicas diárias (STd).

\section{$S T a=\Sigma S T d$}

Com as variáveis número de folhas e altura de plantas foram elaboradas curvas de crescimento ajustadas pelo modelo logístico, descrito por REGAZZI (2003), como:

$$
Y=4 \alpha\left(\exp (-(X-\beta) / \gamma) /\left(1+\left(\exp \left(-\frac{X-\beta}{\gamma}\right)\right)^{2}\right.\right.
$$

Em que: $Y$ é a altura de planta $(\mathrm{cm})$ ou o número de folhas; $X$ representa a soma térmica acumulada ( $\mathrm{STa},{ }^{\circ} \mathrm{C}$ dia); $a$ é a altura ou o número de folhas máximo esperado; $b$ a máxima soma térmica acumulada para o máximo de altura ou o máximo de número de folhas; $g$ é o intercepto; e, exp é a base dos logaritmos neperianos.

A qualidade de ajuste dos modelos foi avaliada pelo coeficiente de determinação $\left(\mathrm{R}^{2}\right)$ e pelo desvio médio absoluto dos resíduos (DMA), calculado como:

$$
D M A=\frac{\sum_{i=0}^{n}|Y i-\hat{Y} i|}{n}
$$

Em que: $Y i$ é o valor observado; $Y i$ é o valor estimado e $n$ é o tamanho da amostra. Quanto menor for o valor obtido, melhor será o ajuste (SARMENTO et al., 2006).

As análises dos dados foram realizadas com a utilização do programa computacional Table Curve 2D v. 2.03 (Jandel Scientific).

\section{RESULTADOS E DISCUSSÃO}

As curvas de crescimento, para a altura de plantas (Figura 1) e para o número de folhas por planta (Figura 2), para as cultivares crioulas e para as progênies de meios-irmãos maternos destas, apresentaram ajustes satisfatórios pelo modelo logístico. Isso se deve aos valores do coeficiente de determinação $\left(\mathrm{R}^{2}\right)$ ficarem acima de 0,85 , e os valores de desvio médio dos resíduos (DMA), principalmente para as cultivares, terem sido considerados baixos (Tabelas 1 e 2).

Em relação aos genótipos avaliados, as cultivares crioulas geralmente apresentaram melhor ajuste. Portanto, observa-se em campo plantas menos heterogêneas que nas progênies e entre as variáveis, número de folhas por planta obteve o melhor ajuste, devido aos valores de $\mathrm{R}^{2}$ superiores a 0,90 e aos menores valores de DMA (Tabelas 1 e 2). Os valores de $\mathrm{R}^{2}$ e DMA indicam que o modelo utilizado explicou a maior parte da variabilidade nas variáveis altura de planta e número de folhas por planta para os genótipos estudados. O ajuste obtido por LYRA et al. (2008), para as curvas de crescimento de altura de plantas e massa seca de folhas, de caule e massa seca total, em função da soma térmica acumulada, para a cultivares de milho avaliadas pelo modelo logístico, foi considerado adequado, pois foram obtidos valores de $\mathrm{R}^{2}$ superiores a 0,86 , o que possibilita a utilização do modelo logístico para o ajuste de curvas de crescimento destas variáveis em função da soma térmica acumulada.

Devido à variabilidade existente na cultura do milho, podem ocorrer diferenças entre os genótipos. No caso do ponto de inflexão (P.I), ponto em que ocorre a máxima taxa de crescimento, a soma térmica média para que as cultivares crioulas atingiram o P.I com 826,21 graus-dia para a variável altura de plantas, enquanto que, para as progênies, este valor foi de 849,20 graus-dia (Tabela 1). Em relação à variável número de folhas por planta, as progênies apresentaram soma térmica inferior à apresentada pelas cultivares crioulas para atingir o P.I, com média 742,19 graus-dia, enquanto as cultivares crioulas necessitaram de 750,85 graus-dia (Tabela 2).

Em relação às variáveis avaliadas para estimar o crescimento, é possível verificar que ocorre primeiramente a formação das folhas para posteriormente ocorrer o incremento em altura nas plantas, que pode ser observado pelo P.I. (Tabelas 1 e 2). Para OLIVEIRA et al. (2013), o acúmulo de massa seca de folhas é mais intenso em um período próximo ao florescimento, enquanto que o maior acúmulo de massa seca no colmo ocorre após este período. Para GARCIA et al. (2008), o maior incremento de massa seca das plantas ocorre em períodos iniciais do ciclo, caso estas sejam influenciadas por diferentes regimes hídricos. Dessa forma, o incremento de massa seca apresenta redução com a continuidade do desenvolvimento das plantas. Portanto, o crescimento das plantas é afetado pela fotossíntese e absorção de nutrientes e água (CARVALHO et al., 2009), sendo condições do ambiente em que está situada $\mathrm{a}$ área de cultivo.

Com relação ao ponto máximo de inflexão da curva de ajuste (assíntota), para a altura de plantas, não foi obtida diferença entre as cultivares crioulas pela comparação dos limites inferiores e superiores do intervalo de confiança, ou seja, o limite superior de uma cultivar está contido no intervalo de confiança da outra cultivar (Tabela 1). No entanto, as progênies de milho crioulo 'Lombo Baio' e 'Oito Carreiras' apresentaram diferença significativa em relação à soma térmica necessária para que atingissem a assíntota. Quanto ao número de folhas por planta, o máximo atingido foi 1083,4 graus-dia para a cultivar 'Amarelão', com a menor soma térmica entre as cultivares, enquanto, 'Lombo Baio' necessitou de 1226,62 graus-dia (Tabela 2). Diferentemente das 




Cultivar Oito Carreiras

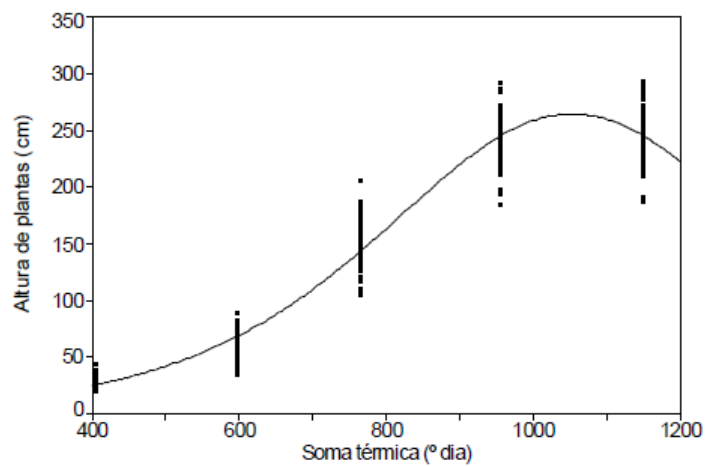

Progênies Lombo Baio

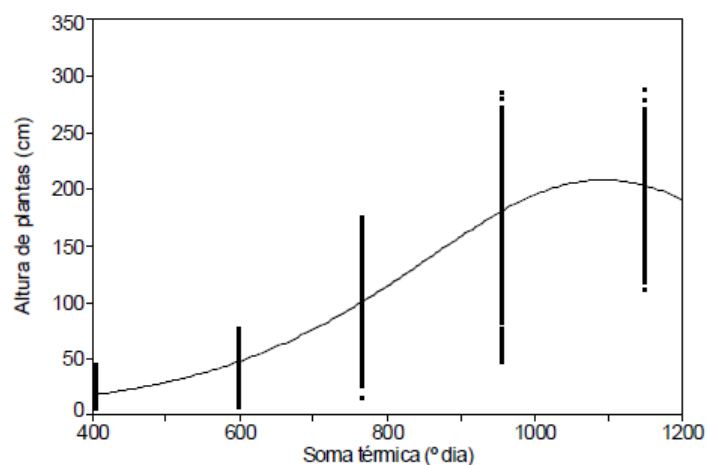

Cultivar Lombo Baio

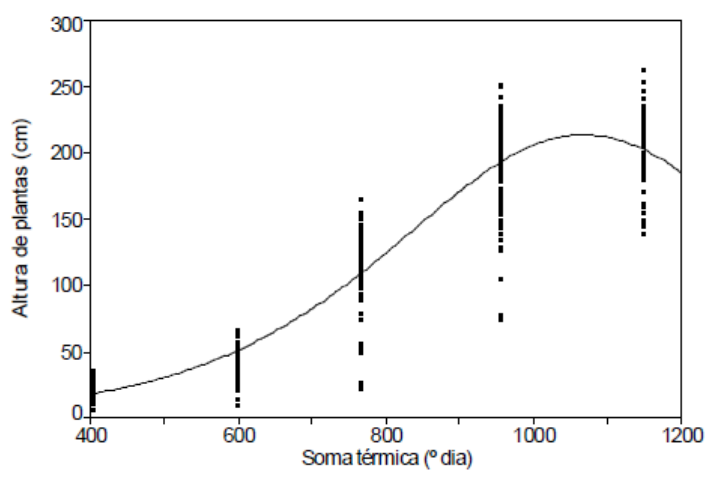

Progênies Amarelão

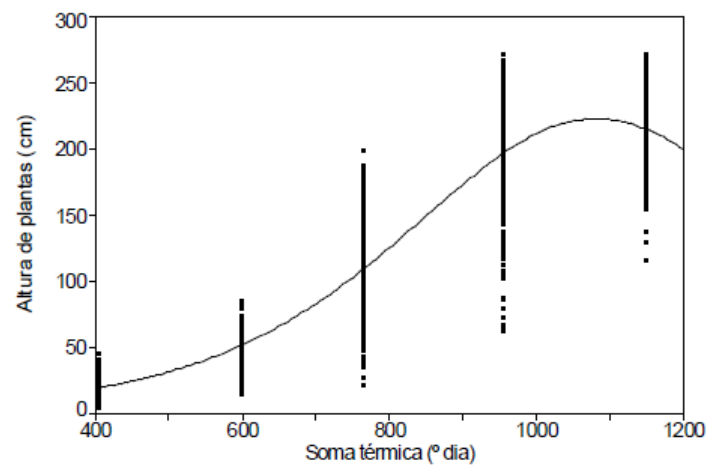

Progênies Oito Carreiras

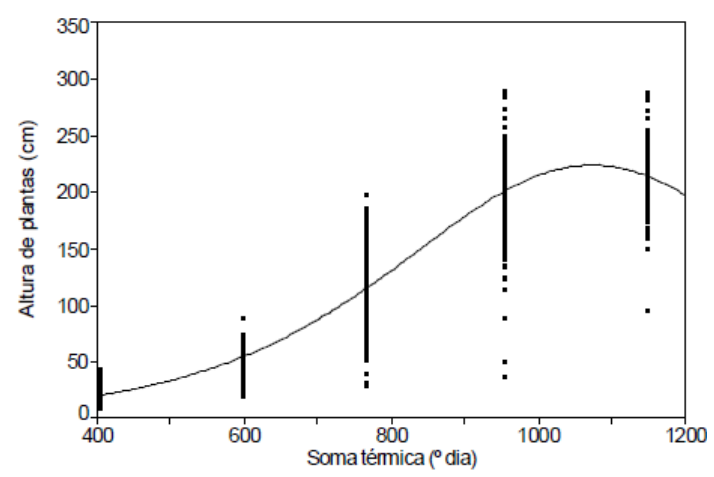

Figura 1 - Curvas de crescimento ajustadas pelo modelo logístico para altura de plantas (cm) (Y) das cultivares crioulas e das progênies de meios-irmãos maternos das cultivares crioulas de milho 'Amarelão', 'Lombo Baio' e 'Oito Carreiras' e em função da soma térmica acumulada $\left({ }^{\circ} \mathrm{C}\right.$ dia $)(\mathrm{X})\left(\mathrm{Y}=4 \alpha\left(\exp (-(\mathrm{X}-\beta) / \gamma) /\left(1+(\exp (-(\mathrm{X}-\beta) / \gamma))^{\wedge} 2\right)\right.\right.$. Santa Maria, $\mathrm{RS}, 2013$.

cultivares crioulas, apenas as progênies da cultivar 'Lombo Baio' diferiram das demais para atingir a assíntota. Nesse caso, a soma térmica acumulada foi de 1184,07 graus-dia, superior às demais progênies avaliadas. Os dados indicam a ocorrência de ciclo mais longo para as progênies, exceto as progênies de 'Lombo Baio', que apresentaram soma térmica inferior à obtida pela cultivar, para atingir a assíntota. 


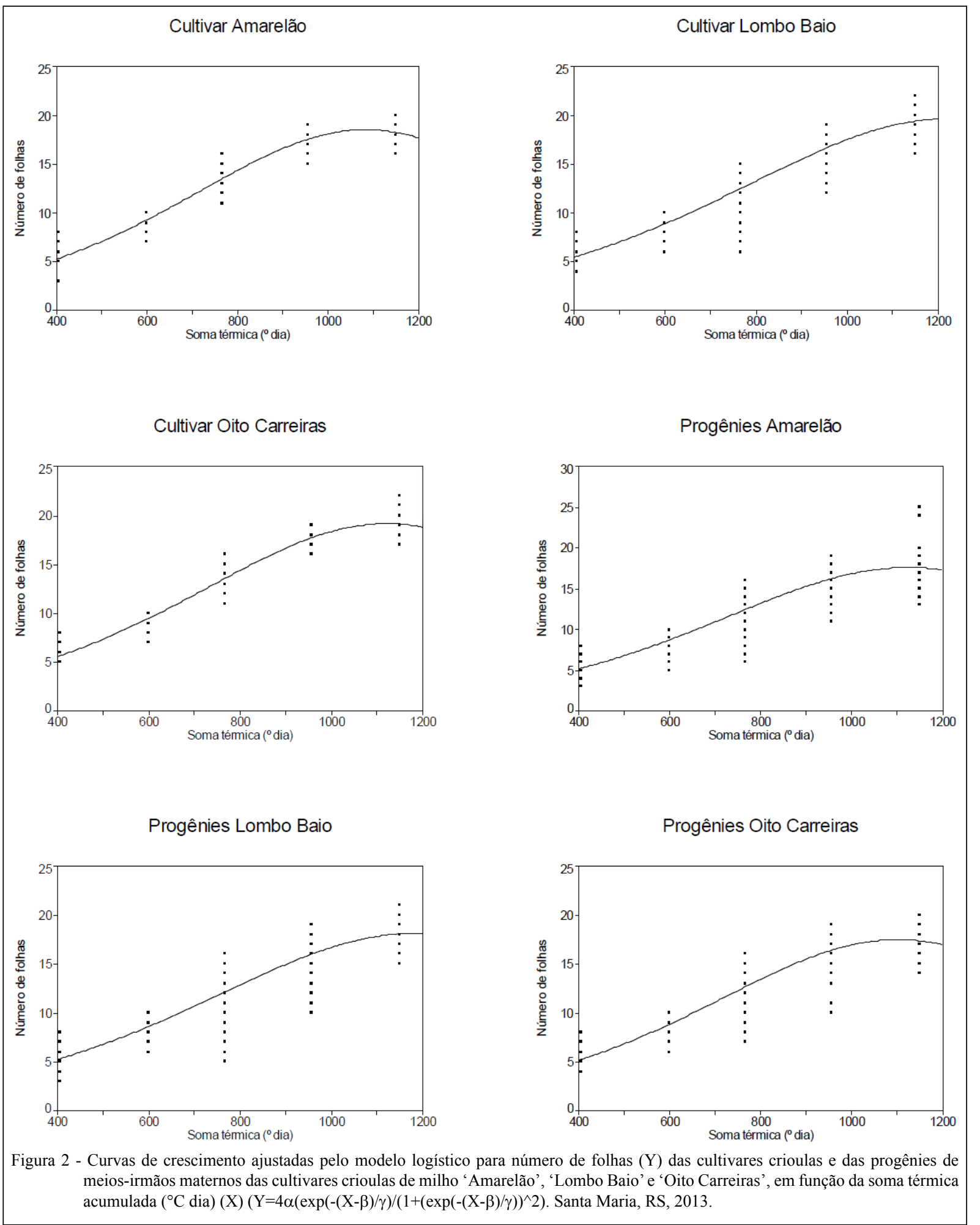

Os genótipos que apresentam menor soma térmica acumulada para completar o ciclo da cultura permanecem menos tempo em campo (ZUCARELI et al., 2013), o que reduz os riscos de perdas com clima e pragas. No entanto, a ocorrência de estresses hídricos pode tornar o ciclo mais longo e, consequentemente, a soma térmica acumulada é superior à obtida em um ciclo sem restrições (LYRA et al., 2008). A redução 
Tabela 1 - Estimativas e limites superior (LS) e inferior (LI) do intervalo de confiança dos parâmetros $\alpha$, $\beta$ e $\gamma$, ponto de inflexão ( P.I - ${ }^{\circ} \mathrm{C}$ dia), coeficiente de determinação $\left(\mathrm{R}^{2}\right)$ e desvio médio absoluto (DMA), do modelo logístico para a altura de plantas (cm) em função da soma térmica $\left({ }^{\circ} \mathrm{C}\right.$ dia) de cultivares crioulas de milho 'Amarelão', 'Lombo Baio' e 'Oito Carreiras' e de progênies de meios-irmãos maternos. Santa Maria, RS, 2013.

\begin{tabular}{|c|c|c|c|c|c|c|}
\hline Cultivares & $\alpha$ & $\beta$ & $\gamma$ & P.I & $\mathrm{R}^{2}$ & DMA \\
\hline 'LS' & 241,21 & 1056,77 & 183,21 & & & \\
\hline ‘Amarelão' & 237,90 & 1049,22 & 177,84 & 815,01 & 0,95 & 12,76 \\
\hline 'LI' & 234,60 & 1041,67 & 172,46 & & & \\
\hline 'LS' & 217,40 & 1079,79 & 181,51 & & & \\
\hline 'Lombo Baio' & 213,10 & 1068,01 & 173,47 & 839,55 & 0,90 & 16,66 \\
\hline 'LI' & 208,80 & 1056,23 & 165,44 & & & \\
\hline 'LS' & 266,94 & 1059,95 & 178,78 & & & \\
\hline 'Oito Carreiras' & 263,66 & 1053,32 & 174,08 & 824,07 & 0,96 & 13,42 \\
\hline 'LI' & 260,38 & 1046,70 & 169,37 & & & \\
\hline 'LS' & 224,52 & 1088,28 & $\begin{array}{c}\text { rogênies } \\
180,20\end{array}$ & - & ------ & 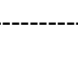 \\
\hline ‘Amarelão' & 222,41 & 1081,99 & 176,11 & 850,05 & 0,90 & 18,37 \\
\hline 'LI' & 220,30 & 1075,69 & 172,03 & & & \\
\hline 'LS' & 209,18 & 1101,12 & 184,11 & & & \\
\hline 'Lombo Baio' & 207,13 & 1093,72 & 179,53 & 857,29 & 0,85 & 22,21 \\
\hline 'LI' & 205,18 & 1086,32 & 174,95 & & & \\
\hline 'LS' & 225,99 & 1082,07 & 182,81 & & & \\
\hline 'Oito Carreiras' & 222,91 & 1073,36 & 177,01 & 840,25 & 0,89 & 18,65 \\
\hline 'LI' & 219,82 & 1064,64 & 171,20 & & & \\
\hline
\end{tabular}

Tabela 2 - Estimativas e limites superior (LS) e inferior (LI) do intervalo de confiança dos parâmetros $\alpha$, $\beta$ e $\gamma$, ponto de inflexão ( P.I - ${ }^{\circ} \mathrm{C}$ dia), coeficiente de determinação $\left(\mathrm{R}^{2}\right)$ e desvio médio absoluto (DMA), do modelo logístico para o número de folhas por planta em função da soma térmica $\left({ }^{\circ} \mathrm{C}\right.$ dia) de cultivares crioulas de milho 'Amarelão', 'Lombo Baio' e 'Oito Carreiras' e de progênies de meios-irmãos maternos. Santa Maria, RS, 2013.

\begin{tabular}{|c|c|c|c|c|c|c|}
\hline Cultivares & $\alpha$ & $\beta$ & $\gamma$ & P.I & $\mathrm{R}^{2}$ & DMA \\
\hline 'LS' & 18,63 & 1095,71 & 282,01 & & & \\
\hline ‘Amarelão’ & 18,46 & 1083,40 & 274,26 & 722,20 & 0,96 & 0,86 \\
\hline 'LI' & 18,30 & 1071,09 & 266,52 & & & \\
\hline 'LS' & 20,04 & 1262,32 & 344,52 & & & \\
\hline 'Lombo Baio' & 19,61 & 1226,62 & 328,60 & 793,86 & 0,94 & 1,01 \\
\hline 'LI' & 19,18 & 1190,92 & 312,68 & & & \\
\hline 'LS' & 19,28 & 1138,36 & 302,12 & & & \\
\hline 'Oito Carreiras' & 19,10 & 1122,45 & 293,07 & 736,49 & 0,96 & 0,83 \\
\hline 'LI' & 18,92 & 1106,55 & 284,02 & & & \\
\hline- & 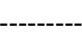 & ----------- & Progênies & --------- & ------ & ------. \\
\hline 'LS' & 17,67 & 1137,19 & 302,19 & & & \\
\hline ‘Amarelão’ & 17,56 & 1125,99 & 295,86 & 736,35 & 0,91 & 1,12 \\
\hline 'LI' & 17,44 & 1114,79 & 289,53 & & & \\
\hline 'LS' & 18,22 & 1197,62 & 324,17 & & & \\
\hline 'Lombo Baio' & 18,07 & 1184,07 & 317,50 & 765,93 & 0,91 & 1,16 \\
\hline 'LI' & 17,93 & 1170,51 & 910,83 & & & \\
\hline 'LS' & 17,58 & 1115,97 & 295,25 & & & \\
\hline 'Oito Carreiras' & 17,43 & 1102,24 & 287,00 & 724,28 & 0,91 & 1,13 \\
\hline 'LI' & 17,27 & 1088,51 & 278,75 & & & \\
\hline
\end{tabular}


do ciclo também pode ocorrer quando a semeadura é adiada, pois, nesses casos, ocorre a redução do período vegetativo, o que, consequentemente, reduz o ciclo das plantas (GADIOLI et al., 2000).

A altura de plantas diferiu entre cultivares crioulas e progênies de meios-irmãos de 'Amarelão' e 'Oito Carreiras', pelos limites inferior e superior do intervalo de confiança (Tabela 1), sendo que as progênies desta última se destacaram com redução superior a $30 \mathrm{~cm}$. Mesmo não tendo apresentado diferença significativa entre cultivares e progênies, também foram obtidas plantas mais baixas nas progênies de 'Lombo Baio' em comparação a altura das plantas da cultivar crioula. A diferença foi significativa para as cultivares crioulas e respectivas progênies de meios-irmãos maternos para a variável número de folhas por planta (Tabela 2), pela comparação dos limites superior e inferior do intervalo de confiança, ou seja, o limite superior para a cultivar não está contido no intervalo de confiança das progênies, sendo que as progênies emitiram menor número de folhas por planta.

A emissão de folhas pode ter sua velocidade afetada, dependendo das condições ambientais, como o tipo de solo. No entanto, a quantidade final de folhas não é afetada, sendo esta uma característica com grande influência genética (ANDREOTTI et al., 2001). Para LOPES et al. (2009), o aumento do índice de área foliar das plantas de milho resulta em maior taxa de crescimento da cultura em plantio convencional, o que está de acordo com os resultados obtidos, pois ocorreu redução tanto da altura das plantas como do número de folhas por planta para as progênies em relação às cultivares crioulas.

\section{CONCLUSÃO}

As cultivares crioulas 'Amarelão' e 'Oito Carreiras' apresentam maior altura de plantas e maior número de folhas por planta, em comparação às respectivas progênies de meios-irmãos maternos, enquanto a cultivar 'Lombo Baio' não apresenta diferença significativa entre cultivar e progênies para altura de plantas, mas sim um maior número de folhas por planta, quando comparada às progênies.

\section{AGRADECIMENTOS}

Os autores agradecem ao Conselho Nacional de Desenvolvimento Científico e Tecnológico (CNPq) (Processo 563991/2010-0) e a Coordenação de Aperfeiçoamento de Pessoal de Nível Superior (CAPES) pelo auxílio financeiro.

\section{REFERÊNCIAS}

ANDREOTTI, M. et al. Crescimento do milho em função da saturação por bases e da adubação potássica. Scientia Agricola, v.58, n.1, p.145-150, 2001. Disponível em: <http://www.scielo. br/pdf/sa/v58n1/a22v58n1.pdf $>$. Acesso em: 2 jun. 2014. doi: 10.1590/S0103-90162001000100022.

ARAÚJO, P.M.; NASS, L.L. Caracterização e avaliação de populações de milho crioulo. Scientia Agricola, v.59, n.3, p.589-593, 2002. Disponível em: <http://www.scielo.br/scielo. php? script $=$ sci_arttext\&pid $=$ S01 03-90162002000300027>. Acesso em: 20 jun. 2012. doi: 10.1590/S0103-90162002000300027.

CARVALHO, C.A.L. et al. Tópicos em ciências agrárias. Cruz das Almas: Universidade Federal do Recôncavo da Bahia, 2009. V.1, 296p.

COIMBRA, R.R. et al. Caracterização e divergência genética de populações de milho resgatadas do Sudeste de Minas Gerais. Revista Ciência Agronômica, v.41, n.1, p.159-166, 2010. Disponível em: $<$ http://ccarevista.ufc.br/seer/index.php/ccarevista/ article/view/347>. Acesso em: 15 mar. 2014.

DOURADONETO, D. etal. Principles of crop modeling and simulation. I. Uses of mathematical models in agriculture science. Scientia Agricola, v.55, p.46-50, 1998. Disponível em: <http://www.scielo. br/scielo.php?script=sci_arttext\&pid=S0103-90161998000500008>. Acesso em: 9 set. 2013. doi: 10.1590/S0103-90161998000500008.

GADIOLI, J.L. et al. Temperatura do ar, rendimento de grãos de milho e caracterização fenológica associada à soma calórica. Scientia Agricola, v.57, n.3, p.377-383, 2000. Disponível em: $<$ http://www.scielo.br/pdf/sa/v57n3/2663.pdf $>$. Acesso em: 29 jun. 2012. doi: 10.1590/S0103-90162000000300001.

GARCIA, A. et al. Análise de crescimento de uma cultura de milho submetida a diferentes regimes hídricos. Nucleus, v.5, n.1, p. $239-$ 251, 2008. Disponível em: $<$ http://www.nucleus.feituverava.com. br/index.php/nucleus/article/view/60>. Acesso em: 29 jan. 2014. doi: 10.3738/nucleus.v5i1.60.

LYRA, G.B. et al. Modelo de crescimento logístico e exponencial para o milho BR 106, em três épocas de plantio. Revista Brasileira de Milho e Sorgo, v.7, n.3, p.211-230, 2008. Disponível em: <http:// rbms.cnpms.embrapa.br/index.php/ojs/article/viewArticle/290>. Acesso em: 24 fev. 2014.

LOPES, J.P. et al. Análise de crescimento e trocas gasosas na cultura de milho em plantio direto e convencional. Bragantia, v.68, n.4, p.839-848, 2009. Disponível em: $<$ http://www.scielo.br/ scielo.php?script $=$ sci_arttext\&pid $=\mathrm{S} 0006-87052009000400003>$. Acesso em: 16 maio 2014 doi: 10.1590/S000687052009000400003 .

OLIVEIRA, P. et al. Crescimento e produtividade de milho em função da cultura antecessora. Pesquisa Agropecuária Tropical, v. 43, n. 3, p. 239-246, 2013. Disponível em: <http://www.revistas. ufg.br/index.php/pat/article/view/22077>. Acesso em: 1 mar. 2014.

PATERNIANI, E. et al. O valor dos recursos genético de milho para o Brasil: uma abordagem histórica da utilização do germoplasma. In: UDRY, C.V.; DUARTE, W.F. (Org.). Uma história brasileira do milho - o valor de recursos genéticos. Brasília: Paralelo 15, 2000. p.11-41. 
REGAZZI, A.J. Teste para verificar a igualdade de parâmetros e a identidade de modelos de regressão não-linear. Revista Ceres, v.50, n.287, p.9-26, 2003.

REINERT, D.J. et al. Principais solos da depressão central e campanha do Rio Grande do Sul: guia de excursão. 2 ed. Santa Maria: Departamento de Solos - UFSM, 2007. 47p.

SARMENTO, J.L.R. et al. Estudo da curva de crescimento de ovinos da raça Santa Inês. Revista Brasileira de Zootecnia, v.35, n.02, p.435-442, 2006.
SILVA, L.C. et al. Análise do crescimento de comunidades vegetais. Campina Grande, PB: Embrapa Algodão, 2000. 18p. (Circular Técnica 34).

TEIXEIRA, F.F.; COSTA, M.F. Caracterização de recursos genéticos de milho. Sete Lagoas: Embrapa Milho e Sorgo, 2010. 10p. (Comunicado Técnico 155).

ZUCARELI, C. et al. Desempenho agronômico de genótipos de milho de segunda safra na região norte do Paraná. Scientia Agraria Paranaensis, v.12, n.3, p.227-235, 2013. Disponível em: <http://e-revista.unioeste.br/index.php/scientiaagraria/article/ view/5593>. Acesso em: 2 mar. 2014. 